\title{
CARACTERÍSTICAS MICROBIOLÓGICAS DE CARNE DE SIRI BENEFICIADA EM ANTONINA (PR) ANTES E APÓS A ADOÇÃO DE MEDIDAS DE BOAS PRÁTICAS
}

\author{
Denise Maria VIEIRA ${ }^{1}$ \\ Carlos Roberto Conti NAUMANN² \\ Takaaki ICHIKAWA ${ }^{3}$ \\ Lys Mary Bileski CÂNDIDO4
}

\begin{abstract}
RESUMO
A carne de siri produzida em Antonina (PR) tradicionalmente é beneficiada e comercializada informalmente, em condições muitas vezes precárias. Na unidade de beneficiamento de pescado Serramar buscou-se a implantação de um modelo de produção industrial. A adoção das boas práticas de fabricação é necessária para garantir a qualidade e segurança dos alimentos. O objetivo do trabalho foi verificar o efeito da adoção de medidas de boas práticas sobre a qualidade microbiológica da carne de siri beneficiada. Como instrumento de avaliação utilizou-se análise microbiológica da água de abastecimento e da carne de siri beneficiada na unidade. As amostras de carne de siri foram distribuídas em quatro grupos: grupo I - antes das alterações na higienização dos objetos e utensílios e mãos, tempo de exposição da carne de siri à temperatura ambiente e uso de luva; grupo ll após adoção de medidas de boas práticas de fabricação referentes a higienização dos objetos, utensílios e mãos; grupo III após adoção das medidas de higienização, juntamente com a diminuição do tempo de exposição da carne de siri à temperatura ambiente e grupo IV posteriormente à adoção de medidas de higienização, diminuição do tempo de exposição e utilização de luva. Aágua de abastecimento não apresentou crescimento microbiológico. A análise microbiológica da carne de siri apresentou os seguintes resultados: contaminação por mesófilos e número mais provável (NMP) de coliformes totais mais alta no grupo le decrescente à medida que foram adotadas as boas práticas. O NMP de coliformes termotolerantes foram altos no grupo I, com decréscimo nos grupos subseqüentes, havendo crescimento não esperado no grupo 4. Esse crescimento pode estar relacionado com contaminações da água do mar e cozimento inadequado. Em todas as amostras foi negativa a pesquisa de Salmonela sp. A pesquisa de Staphylococcus aureus apresentou-se em desacordo com a legislação nos 3 primeiros grupos e dentro do limite no grupo 4. Para o beneficiamento do siri a adoção de procedimentos de higienização e diminuição do tempo de exposição são insuficientes para prevenir o crescimentos $S$. aureus, sendo necessário o uso de luvas. Os resultados apresentados reforçam a necessidade da adoção de medidas de treinamento, capacitação pessoal e monitoramento da qualidade da água do mar e adequação de condições higiênico-sanitárias.
\end{abstract}

Palavras-chave: Carne de siri; contaminação microbiológica; boas práticas de fabricação.

\begin{abstract}
The crab meat that is produced in Antonina (PR) is traditionally processed and commercialized informally under conditions that are many times precarious. With the Serramar Processing Unit a new model of industrial processing is sought. The adoption of of good manufacturing practices is made necessary to assure quality and safety of the foods. The main goal of this work is to assess the quality of the product by microbiologic analyses, considering the adoption of measures of good manufacturing practices. The microbiologic analysis of the supplied water and the crabmeat processed in the unit was used as an assessing tool. The crab meat samples were distributed in four groups: group I- before the alteration made in the hygiene process of the objects, tools and hands, exposure time of the crab meat to room temperature and the use of gloves; group II - after the adoption of good manufacturing practices for the hygiene process of objects, tools and hands; group III - after the adoption of the hygiene process together with the diminishing of the crab meat exposure time to room temperature and group IV - after the adoption of hygiene measures, diminishing of exposure time and the use of gloves. The supplied water did not present any microbiological growth. The crab meat presented the following results after the analyses: contamination by mesophylic and high total coliform MPN (most probable number), higher in group I and then going down as good practice measures were being adopted. The thermal-tolerant coliform MPN were high in group I, diminishing in the following groups showing an unexpected growth in the group IV. Such growth could be related to seawater contamination and inappropriate cooking. In all samples the presence of Salmonela sp was negative. The search for Staphylococus aureus showed itself in disagreement with the current regulations in the first three groups and within regulation limits in the group IV. For the processing of the crab meat the adoption of hygiene procedures and the diminishing of exposure time had showed themselves insufficient to prevent the growth of $S$. aureus. The use of gloves is made necessary. The results presented reinforce the need for the adoption of good manufacturing practices. There is a need for training and staff's professional upgrading as well as the monitoring of seawater quality and appropriate sanitary-hygienic conditions. Such measures should be included in the good manufacturing practices manual.
\end{abstract}

Key-words: Crab meat; microbiological contamination; good manufacturing practices.

\footnotetext{
${ }^{1}$ Médica Veterinária e Bióloga;

${ }^{2}$ Professor Doutor do Departamento de Medicina Veterinária - UFPR e médico veterinário do SIF - Ministério da Agricultura;

${ }^{3}$ Médico Veterinário chefe do setor de microbiologia de alimentos do LAPA-Laboratório de Apoio Animal - Ministério da Agricultura;

${ }^{4}$ Professora Doutora Sênior da Universidade Federal do Paraná

Endereço de correspondência - Denise Maria Vieira - Rua São Mateus, 580 apto 201 Curitiba- PR CEP 81070-080 - e-Mail: vieira@estadao.com.br
} 


\section{INTRODUÇÃO}

A carne de siri produzida em Antonina ( $\mathrm{Pr}$ ) é beneficiada e comercializada informalmente, em condições muitas vezes precárias. A construção da unidade de beneficiamento de Pescado Serramar buscou a implantação de um modelo de produção industrial. Neste processo é necessária a capacitação dos manipuladores, pessoas que há muito tempo trabalham com estes produtos de forma tradicional.

O siri, como os demais crustáceos, possui um exoesqueleto calcário que lhe dá sustentação e proteção. Esta proteção dificulta o processo de retirada da carne de siri, conhecido como "desmariscagem", abertura e quebra da carapaça permitindo acesso à carne.

O volume e o peso deste material calcário (casca) são grandes quando comparados com a musculatura. São necessárias 5 a 6 dúzias de crustáceos, dependendo do tamanho, para se obter $1 \mathrm{~kg}$ de carne de siri.

A ação dos microrganismos sobre o pescado se inicia no momento da captura e se estende por todas as etapas de processamento. Diversos fatores interferem na natureza e na velocidade dos processos de deterioração (ALVES, 2002). A intensa manipulação na "desmariscagem" do siri é um destes fatores. O contato direto com a água e com o material calcário, que é cortante, provoca constantes ferimentos e machucaduras nas mãos dos manipuladores.

A conservação de pescado requer rigoroso controle de qualidade, da captura à comercialização. O controle da multiplicação de microrganismos propicia obter alimentos mais saudáveis, resultando na eliminação, ou na redução de riscos à saúde do consumidor, além de reduzir o desperdício (ALVES, 2002). Segundo HUSS (1997), a verdadeira incidência de doenças transmitidas por alimentos do mar não é conhecida, e a maioria dos casos não é reportada. Entretanto, há evidências claras que pescado ou produtos de pescado estão no alto da lista de alimentos associados com o afloramento de doenças de origem alimentar.

A análise microbiológica é um instrumento que permite avaliar as condições microbiológicas dos alimentos, contribuindo para a obtenção de produtos de qualidade.

O trabalho teve como objetivos realizar análises microbiológicas da água de abastecimento e de amostras de carne de siri processadas na unidade de beneficiamento de Pescado Serramar e, comparar a qualidade microbiológica dos produtos antes e após a adoção de medidas importantes de "boas práticas", para obtenção de produto de elevada qualidade.

\section{METODOLOGIA}

A metodologia de amostragem aplicada considerou as condições e medidas de boas práticas adotadas e descritas na Tabela 1. As análises seguiram a legislação do Ministério da Saúde (RDC no 12 de 21/10/2002) e metodologia de análises microbiológicas para Alimentos do Ministério da Agricultura, Abastecimento e Reforma Agrária. Cada amostra continha o peso líquido de $250 \mathrm{~g}$. A amostra de carne de siri foi congelada à $-18^{\circ} \mathrm{C}$, encaminhada ao laboratório e, no dia em que antecedeu à análise foi mantida em refrigerador a $4,5^{\circ} \mathrm{C}$, para o descongelamento. As análises foram realizadas no LAPA/PR - (Laboratório de Apoio Animal) do Ministério da Agricultura, Pecuária e Abastecimento. Foram coletadas, ao todo, onze amostras, separadas em 4 grupos: coletas.

- Grupo I: formado pelas $1^{\underline{a}}, 2^{\underline{a}}, 3^{\underline{a}}, 4^{\underline{a}}$ e $5^{\underline{a}}$

- GRUPO III: formado pelas amostras das $8^{a}$, $9^{\text {a }}$ coletas.

- GRUPO IV: formado pelas amostras das 10 e $11^{\text {a }}$ coletas.

Nas amostras de carne de siri foram realizadas as seguintes análises:

- Contagem total de microorganismos mesófilos aeróbios, estritos e facultativos, viáveis, com incubação a $37^{\circ}$. totais;

- Número mais provável (NMP) de coliformes

- Número mais provável (NMP) de coliformes termotolerantes.

- Pesquisa de Salmonella sp.

- Contagem de Staphylococcus aureus

Foram realizadas duas coletas de água de abastecimento e analisadas no LAPA. Nas amostras de água de abastecimento foram realizadas as seguintes análises:

- Contagem total de microorganismos mesófilos aeróbios, estritos e facultativos, viáveis, com incubação a $37^{\circ} \mathrm{C}$.

- Número mais provável (NMP) de coliformes totais;

- Número mais provável (NMP) de coliformes termotolerantes.

\section{RESULTADOS E DISCUSSÃO}

Os resultados das análises para a carne de siri foram apresentados por grupos conforme as condições da colheita da amostra. Os resultados das análises do Grupo I, Grupo II, Grupo III e Grupo IV, por tipo de microrganismo pesquisado, aparecem nas Tabelas 2 a 5 . 
TABELA 1 - Condições e medidas de boas práticas adotadas nas amostras de carne de siri.

\begin{tabular}{|c|c|}
\hline $\begin{array}{c}\text { GRUPO I - Antes das alterações } \\
(5 \text { amostras })\end{array}$ & $\begin{array}{l}\text { a) Higienização dos utensílios com água, } \\
\text { esponja e pouco detergente; com remoção } \\
\text { dos resíduos sólidos; } \\
\text { b) tempo de exposição da carne de siri à } \\
\text { temperatura ambiente entre } 25 \text { a } 30 \text { graus Celsius } \\
\text { entre a manipulação e o congelam ento em torno } \\
\text { de três horas; } \\
\text { c) Não uso de luvas pelos manipuladores }\end{array}$ \\
\hline $\begin{array}{r}\text { GROPO II - Alterações nos procedimentos } \\
\text { de higienização (2 amostras) }\end{array}$ & $\begin{array}{l}\text { d) Higienização dos objetos e utensílios com remoção } \\
\text { dos resíduos sólidos e enxágüe com água; } \\
\text { e) Lavagem com detergente neutro e novo enxágüe } \\
\text { com água } \\
\text { f) Sanitização com solução clorada } 200 \text { ppm e novo } \\
\text { enxágüe com água } \\
\text { g) secagem natural } \\
\text { h) Escovação das unhas e lavagem das mãos com } \\
\text { sabonete líquido (durante } 2 \text { minutos) }\end{array}$ \\
\hline $\begin{array}{l}\text { GROPO III - Alterações nos procedim entos } \\
\text { de higienização e tempo de } \\
\text { exposição à temperatura } \\
\text { Ambiente }\end{array}$ & $\begin{array}{l}\text { Idem itens d,e, f, g e h do grupo III } \\
\text { i) Tempo de exposição da carne de siri a } \\
\text { temperatura ambiente ( } 25 \text { à } 30 \text { graus Celsius) } \\
\text { entre a manipulação e o congelamento em torno } \\
\text { de trinta minutos. }\end{array}$ \\
\hline $\begin{array}{l}\text { GRUPO IV - Alterações nos procedimentos } \\
\text { de higienização; tempo de } \\
\text { exposição à temperatura e } \\
\text { uso de luva }\end{array}$ & $\begin{array}{l}\text { Idem itens d,e, f, g, h e i do grupo II e grupo III } \\
\text { j) Uso de luvas pelos manipuladores durante } \\
\text { a retirada da carne de siri (desmariscagem) }\end{array}$ \\
\hline
\end{tabular}

TABELA 2 - Contagens totais de microrganismos aeróbios estritos e facultativos, viáveis EM UFC/g.

\begin{tabular}{llc}
\hline & & Leitura (UFC/g) \\
\hline Grupo I & Amostra 1 & $1,7 \times 10^{4}$ \\
& Amostra 2 & $2,5 \times 10^{5}$ \\
& Amostra 3 & $2,5 \times 10^{5}$ \\
& Amostra 4 & $2,5 \times 10^{5}$ \\
& Amostra 5 & $3,5 \times 10^{4}$ \\
\hline Grupo II & Amostra 1 & $2,5 \times 10^{5}$ \\
& Amostra 2 & $2,5 \times 10^{5}$ \\
\hline \multirow{2}{*}{ Grupo III } & Amostra 1 & $1,2 \times 10^{4}$ \\
& Amostra 2 & $1,6 \times 10^{4}$ \\
\hline \multirow{2}{*}{ Grupo IV } & Amostra 1 & $6,6 \times 10^{2}$ \\
& Amostra 2 & $5,5 \times 10^{3}$ \\
\hline
\end{tabular}

Contagem de Unidade formadora de colônia por grama (UFC/g) de carne de siri conforme os grupos descritos na tabela 1: Grupo Iantes das alterações; Grupo II - Alterações na higienização dos objetos e utensílios; Grupo III - Alterações na higienização e tempo de exposição da carne de siri à temperatura ambiente; Grupo IV - Alterações na higienização, tempo de exposição da carne de siri à temperatura ambiente e uso de luvas. 
Os resultados mostraram alta contagem total de microorganismo mesófilos aeróbios, estritos e facultativos, viáveis, na carne de siri. É indicativo de que os procedimentos de limpeza e higiene não estão sendo adequados. Segundo Goés et al. (2001) a qualidade é componente fundamental dos alimentos. A segurança é também componente indispensável à qualidade, sendo relevante conhecer as variáveis que podem afetar tais componentes, dentre os quais a condição higiênico-sanitária dos alimentos. O manipulador interfere diretamente, podendo mesmo comprometer a qualidade dos mesmos durante as diferentes fases de produção e industrialização.

Segundo Ganowiak (1994) "existem muitos fatores que se ajudam e se somam àqueles que acelerarão o desencadeamento de reações bioquímicas e bacterianas no pescado, culminando com a aceleração de processos deteriorantes. As práticas sanitárias permeiam todos os fatores relativos à contaminação dos alimentos marinhos, incluindo o meio em que esses organismos são capturados, a manipulação da matéria-prima fresca e o estado das instalações onde o pescado é processado e armazenado".

Alimentos com contagem alta podem ter comprometimento de qualidade, sabor e tempo de prateleira. Notou-se através dos dados (Tabela 2), que o tempo reduzido para 30 minutos para 0 congelamento e o uso de luvas são medidas que demonstram tendências a reduzir o número de bactérias. Tais medidas associadas à correta aplicação de procedimentos de higienização de objetos e utensílios são recomendadas para aumentar a qualidade e segurança do produto. Segundo Alves (2002) o uso do frio na cadeia de produção permite controlar a qualidade final do produto, porque as baixas temperaturas retardam reações químicas e bioquímicas. Franco e Langgraf (1996) relatam que quanto menor for a temperatura, menor será a velocidade das reações bioquímicas ou da atividade microbiana. Segundo Taoukins et al. (1999) a temperatura determina a velocidade da atividade microbiológica, que é a principal causa da deterioração de peixe fresco ou produto de pescado pouco processado, assim sendo, constitui parâmetro determinante para a vida de prateleira. O controle da temperatura é um fator importante nas boas práticas de fabricação.

Quanto à contagem de Staphylococcus aureus (Tabela 3), dos quatro grupos de amostras analisadas, três têm amostra em desacordo e apenas o grupo IV ficou dentro dos limites permitidos pela Resolução RDC no 12 de 21 de outubro de 2002 (BRASIL, 2002).

TABELA 3 - Contagens de Staphylococcus aureus nas amostras de carne de siri em ufc/g.

\begin{tabular}{llc}
\hline & & Leitura (UFC/g) \\
\hline Grupo I & Amostra 1 & $8 \times 10^{2}$ \\
& Amostra 2 & $<1 \times 10^{2}$ \\
& Amostra 3 & $1,2 \times 10^{3}$ \\
& Amostra 4 & $<1 \times 10^{2}$ \\
& Amostra 5 & $<1 \times 10^{2}$ \\
\hline \multirow{2}{*}{ Grupo II } & Amostra 1 & $<1 \times 10^{2}$ \\
& Amostra 2 & $6,6 \times 10^{3}$ \\
\hline \multirow{2}{*}{ Grupo III } & Amostra 1 & $2,3 \times 10^{3}$ \\
& Amostra 2 & $<1 \times 10^{2}$ \\
\hline Grupo IV & Amostra 1 & $<1 \times 10^{2}$ \\
& Amostra 2 & $<1 \times 10^{2}$ \\
\hline
\end{tabular}

Contagem de Unidade formadora de colônia por grama (UFC/g) de carne de siri conforme os grupos descritos na tabela 1: Grupo Iantes das alterações; Grupo II - Alterações na higienização dos objetos e utensílios; Grupo III -Alterações na higienização e tempo de exposição da carne de siri à temperatura ambiente; Grupo IV - Alterações na higienização, tempo de exposição da carne de siri à temperatura ambiente e uso de luvas.

Trabulsi (1989) cita Staphylococcus aureus como um dos principais agentes de intoxicação alimentar. O Staphylococcus aureus é uma das bactérias produtoras de enterotoxina e intoxicação alimentar de maior importância em alguns países, inferior apenas para a Salmonella sp.

Ginegeorgis (1987) cita os principais fatores para o envenenamento alimentar por Staphylococcus aureus nos EEUU (1975-1981), Canadá (1973-1977), Inglaterra e País de Gales (1970-1982). Em 95,6\% dos surtos registrados nos EEUU, temperaturas impróprias de manuseio foram fatores chave. Condições precárias de higiene pessoal foi o segundo fator mais importante $(44,6 \%)$, seguido de 
equipamentos contaminados $(21,4 \%)$ e cozimento inadequado $(10,1 \%)$. No Canadá, o resfriamento inadequado foi a chave em $60,6 \%$ dos casos, seguido de trabalhadores infectados (18\%), manuseio impróprio de alimentos $(13,1 \%)$, uso de sobras $(11,5 \%)$, cozimento inadequado $(6,5 \%)$, manuseio quente inadequado $(6,5 \%)$ e vazamento após processamento (6,5\%). Na Inglaterra e País de Gales a preparação do alimento muito antes do consumo foi um fator chave presente em $48,2 \%$ dos casos seguido por estocagem de alimentos em temperatura ambiente $(45,4 \%)$, manipuladores de alimentos infectados $(30,1 \%)$, alimentos abertos frescos contaminados $(25,3 \%)$ e alimentos processados contaminados, excluindo enlatados (16,3\%).

O beneficiamento da carne de siri produzida pela Unidade de Beneficiamento Serramar apresenta deficiências nos processos de higienização de objetos, utensílios e mãos; apresenta também longo tempo de exposição do produto à temperatura ambiente, favorecendo a multiplicação bacteriana; associada também à intensa manipulação e presença de ferimentos nas mãos dos manipuladores.

Os manipuladores de alimentos exercem um papel significativo nas toxinfecções alimentares causadas por Staphylococcus aureus, freqüentemente encontrado nas lesões sépticas das mãos (BRITO; JOSINO e COUTINHO, 2004). A contagem de $S$. aureus está relacionada com o controle da qualidade higiênico-sanitária da produção de alimentos, condição em que a bactéria serve como indicador de contaminação pós-processso ou das condições de sanitização das superfícies destinadas ao contato com o alimento (GERMANO e GERMANO, 2001).

Segundo Vieira, 2004, um dos grandes problemas no processamento dos caranguejos é o tratamento manual utilizado para se retirar a carne das patas e do corpo do animal, depois dos indivíduos terem sofrido um cozimento rápido. Essa operação pode ser fonte de contaminação, principalmente de estafilococos. O uso de luvas e a aplicação de boas práticas de higiene, aliadas à manutenção das temperaturas adequadas e esfriamento rápido da carne evitam esse problema no processamento de caranguejo. Fato semelhante ocorre com o processamento da carne de siri.

Considerando o tipo de atividade para o beneficiamento da carne de siri, os manipuladores apresentam ferimentos nas mãos. Tais condições são favoráveis ao crescimento destes microrganismos, que são habitantes naturais da pele, principalmente $e$ em maior números encontrados na pele lesionada. A adoção apenas de procedimentos de higienização das mãos e utensílios e objetos, juntamente com a redução no tempo de exposição da carne de siri à temperatura ambiente, mostrou insuficiente nestes casos, necessitando-se o uso de luvas pelos manipuladores.

Em nenhuma amostra foi observado crescimento de Salmonella sp. Contudo, o uso de luvas e medidas eficientes de boas práticas previnem a contaminação dos alimentos por este patógeno. Conforme a legislação não é permitida a presença de Salmonella sp na carne de siri.

O processamento e preparo higiênico dos alimentos têm sido observados por muitos anos como requerimentos básicos e de primeira linha na defesa contra microrganismos patogênicos. Entretanto, estas medidas são incapazes de assegurar produtos da pesca livres de patógenos; boa higiene, sanitização e limpeza são necessárias para assegurar a redução dos níveis destes organismos no produto final (HUSS, 1997). A aplicação correta de procedimentos de processamento, higienização e sanitização, contribuem para a prevenção da multiplicação de Salmonella sp.

A analise dos dados da NMP de coliformes totais (Tabela 4) permite observar que o crescimento é alto no primeiro grupo de amostras, contudo quando adotadas as medidas de boas práticas, os valores decrescem. O conjunto de medidas de higienização, controle de tempo para o congelamento e uso de luva pelos manipuladores, quando feito corretamente é eficiente para o controle de Coliformes totais, corroborando as com medidas exigências do Ministério da Agricultura e abastecimento através da Portaria no 368, de 04 de setembro de 1997 e o Ministério da Saúde e pela Portaria no 326 , de 30 de julho de 1997.

A limpeza e a desinfecção são, sem dúvida, operações fundamentais quando se manipula com alimentos e muitas vezes isto é negligenciado ou efetuado em condições inadequadas. Como vários tipos de microrganismos patogênicos se desenvolvem sob tais condições, a desinfecção das instalações, área e equipamentos, proporcionaram redução na contaminação (GOES, FURTUNATO, VELOSO e SANTOS, 2001).

Os valores do NMP de coliformes termotolerante observados na (Tabela 5) estão dentro das exigências (limite máximo tolerado $5 \times 10 / g$ e limite mínimo 10). Contudo observou-se um pequeno crescimento não esperado de coliformes termotolerantes, no grupo IV.

A presença de bactérias do grupo coliformes termotolerantes ou também chamados fecais no alimento é interpretada como indicador de contaminação fecal, ou seja, de condições higiênicosanitárias insatisfatórias, visto que a população desse grupo é constituída de uma alta proporção de Escherichia coli, indicando assim uma possível ocorrência de patógenos entéricos (BRITO, 2003). 
VIEIRA, D.M. et al. Características microbiológicas de...

TABELA 4 - Número mais provável (NMP) de coliformes totais por grama.

\begin{tabular}{llc}
\hline & & Leitura (NMP/g) \\
\hline Grupo I & Amostra 1 & $2,3 \times 10$ \\
& Amostra 2 & $>1,1 \times 103$ \\
& Amostra 3 & $<3$ \\
& Amostra 4 & $>1,1 \times 103$ \\
& Amostra 5 & $>1,1 \times 103$ \\
\hline Grupo II & Amostra 1 & $<3$ \\
& Amostra 2 & 4 \\
\hline \multirow{2}{*}{ Grupo III } & Amostra 1 & $4,3 \times 10$. \\
& Amostra 2 & 9 \\
\hline Grupo IV & Amostra 1 & $4,3 \times 10$ \\
& Amostra 2 & $2,3 \times 10$ \\
\hline
\end{tabular}

Contagem do Número Mais Provável (NMP/g) de coliformes totais em carne de siri conforme os grupos descritos na tabela 1: Grupo I - antes das alterações; Grupo II -Alterações na higienização dos objetos e utensílios; Grupo III -Alterações na higienização e tempo de exposição da carne de siri à temperatura ambiente; Grupo IV - Alterações na higienização, tempo de exposição da carne de siri à temperatura ambiente e uso de luvas.

TABELA 5 - Número mais provável (NMP) de coliformes termotolerantes por grama.

\begin{tabular}{ccc}
\hline & & Leitura (NMP/g) \\
\hline Grupo I & Amostra 1 & $<3$ \\
& Amostra 2 & $<3$ \\
& Amostra 3 & 4 \\
& Amostra 4 & $<3$ \\
& Amostra 5 & $<3$ \\
\hline \multirow{2}{*}{ Grupo II } & Amostra 1 & $<3$ \\
& Amostra 2 & $<3$ \\
\hline Grupo III & Amostra 1 & $<3$ \\
& Amostra 2 & $<3$ \\
\hline \multirow{2}{*}{ Grupo IV } & Amostra 1 & 4 \\
& Amostra 2 & $<3$ \\
\hline
\end{tabular}

Contagem de Número Mais Provável de coliformes termotolerantes/grama (NMP/g) de carne de siri conforme os grupos descritos na tabela 1: Grupo I - antes das alterações; Grupo II - Alterações na higienização dos objetos e utensílios; Grupo III - Alterações na higienização e tempo de exposição da carne de siri à temperatura ambiente; Grupo IV -Alterações na higienização, tempo de exposição da carne de siri à temperatura ambiente e uso de luvas.

Bactérias potencialmente patogênicas encontradas em pescados são causadoras de toxinfecções alimentares. A maioria desses microrganismos relaciona-se à qualidade da água no local de captura e da utilizada na produção de gelo e em outros procedimentos pós-captura (ALVES, 2002). Segundo Vieira (2004), um dos agentes etiológicos das infecções entéricas é a bactéria Escherichia coli que, presente em águas ou alimentos, indica uma contaminação de origem fecal e um possível risco a saúde.O grupo coliforme fecal é restrito aos organismos que crescem no trato gastrintestinal do homem e de animais de sangue quente. Por não fazer parte da microbiota do pescado marinho, a presença de E.coli está associada à contaminação fecal da água do local de captura e/ou do transporte e manuseio que, ocasionalmente tenham entrado em contato com o pescado fresco (GASPAR Jr; VIEIRA e TAPIA, 1997).

A baia de Antonina abriga uma alta carga de contaminantes, comprometendo a qualidade de suas águas (MACHADO e SÁ, 2005). Esta condição pode ter contribuído para a contaminação do produto final com coliformes fecais. São necessárias medidas mais efetivas para minimizar tal risco. Deve-se considerar as seguintes medidas que provavelmente prejudiquem a qualidade do produto:

a) a não escovação dos siris quando chegam na unidade, considerando que a baia de Antonina recebe uma carga grande de poluentes orgânicos.

b) tempo de cozimento insuficiente e grande 
quantidade de siri por batelada; exceder a capacidade pode levar a distribuição do calor desigual, não inviabilizando as bactérias que estejam na superfície do animal e, maior tolerância ao aquecimento dos coliformes termotolerantes.

Medidas práticas que podem auxiliar na melhoria da qualidade e segurança do produto, reduzindo a multiplicação bacteriana:

a) refrigeração das áreas de manipulação e embalagem;

b) higiene e sanitização de todo o ambiente, móveis, utensílios e objetos de forma e freqüência corretas, utilizando produtos regulamentados pelo Ministério da Saúde; c) treinamento e capacitação dos manipuladores, com noções de higiene e saúde;

d) procedimentos corretos de higienização das mãos e uso obrigatório de luvas;

e) afastamento de manipuladores que apresentem quaisquer problemas de pele ou ferimentos nas mãos, braços, rosto, orelhas, nariz;

f) escovações dos siris quando chegam à unidade, respeitar a capacidade e tempo de cozimento;

g) atendimento às etapas descritas no manual de boas práticas.

Os resultados das análises microbiológicas da água encontram-se na Tabela 6.

TABELA 6 - Análises realizadas de água de abastecimento da unidade de beneficiamento de pescado.

\begin{tabular}{lcc}
\hline Amostras de água & $1^{\text {a }}$ amostra & $2^{a}$ amostra \\
\hline Cont. total de MO aeróbios, estritos e fac., viáveis & $<1,0$ UFC $/ \mathrm{ml}$ est & $<1,0$ UFC $/ \mathrm{ml}$ est. \\
NMP coliformes totais & $<0,03 / \mathrm{ml}$ & $<0,03 / \mathrm{ml}$ \\
NMP coliformes termotolerantes & $<0,03 / \mathrm{ml}$ & $<0,03 / \mathrm{ml}$ \\
\hline
\end{tabular}

As análises da água de abastecimento se mostraram de acordo com a legislação, Instrução Normativa 62, itens "a" e "d", publicada em 18/09/ 2003 e, com isso não contribuintes para contaminação do produto.

\section{CONCLUSÃO}

A aplicação de tecnologia de produto, não é garantia de que o produto é totalmente seguro para o consumo. Deve-se conciliar treinamento, capacitação dos envolvidos no processo produtivo, bem como condições higiênico-santárias que devem ser previstas no manual de boas práticas de fabricação.

A carne de siri da unidade de beneficiamento Serramar, considerando-se as medidas de boas práticas propostas, estaria em desacordo com a legislação vigente no critério da contagem de Staphylococcus aureus. Contudo, somente com a adoção de luva pelos manipuladores, todos os critérios exigidos foram atendidos, inclusive na contagem de Staphylococcus aureus.

\section{REFERÊNCIAS}

1. ALVES, C.L; CARVALHO, F. de L. N.; GUERRA, C. G.; ARAÚJO, W. M. M. Comercialização de pescado no Distrito Federal: Avaliação das condições. Higiene Alimentar, v. 16, n. 102/103, p. 41- 49, novembro/dezembro 2002.

2. BRASIL. Instrução Normativa 62 de $26 / 08 / 2003$. Oficializa os métodos analíticos oficiais para análise microbiológica para controle de produtos de origem animal e água. Diário Oficial do União, Brasília, 18/09/2003.

3. BRASIL. Portaria 326 de julho de 1997. Aprova regulamento técnico sobre as condições higiênico-sanitárias e de boas práticas de fabricação para estabelecimentos produtores/industrializadores de alimentos. Diário Oficial da União, Brasília, 01 ago.1997.

4. BRASIL. Portaria 368 de 04 de setembro de 1997. Aprova o regulamento técnico sobre as condições higiênico-sanitárias e de boas práticas de fabricação para estabelecimento elaboradores/industrializadores de alimentos. Diário Oficial da União, Brasília 08 de setembro de 1997.

5. BRASIL.RDC № 12 de 02 de janeiro de 2001. Aprova o Regulamento técnico sobre padrões microbiológicos para alimentos. Diário Oficial da União, Brasília, 10 de janeiro de 2001.

6. BRITO, G.; CORDEIRO, L. N.; JOSINO, S. A.; DE MELO, M. L.; COUTINHO, H. D. M. Avaliação da qualidade microbiológica de hambúrgueres e cachorros - quentes comercializados por vendedores ambulantes no município de Juazeiro do Norte, CE. Higiene Alimentar, v.17, n.110, p. 90-94, 2003

7. FRANCO, B. D. G.; LANDGRAF, M. Microbiologia dos alimentos. São Paulo: Atheneu, 1996.

8. GANOWIAK, Z. M. La sanidade $n$ la industria alimentaria marina. In SIKORSKI, Z. E. (Ed). Tecnologia de los produtos del mar: recursos, composición nutritiva y conservación. Zaragoza: Acribia, p. 289-313, 1994

9. GASPAR Jr.; VIEIRA, R. H. S. Dos F e TAPIA, M. S. R. Aspecto sanitário do pescado de origem de água doce e marinha, comercializado na feira de Gentilândia, Fortaleza - Ceará. Higiene Alimentar, v. 11, n. 51, p. 20 -23, ano 1997.

10. GERMANO, P. M. L. e GERMANO, M. I. S, Higiene e Vigilância Sanitária de Alimentos. São Paulo. Livraria Varela, p. 235238,2001

11. GINEGIORGES, C. Present state of knowlwdge on Staphylococcal intoxication. Journal of Food Microbiology, $\mathrm{n} 9,327-360$, 1987.

12. GOES, J. A. W; FURTUNATO, D. M. DA N.; VELOSO, I. S.; SANTOS, J. M. Capacitação dos manipuladores de alimentos e a qualidade da alimentação servida. Higiene Alimentar, v. 15, n. 82, p.20-22. março 2001

13. HUSS, H.H. Control of indigenous pathogenic bacteria in seafood. Food control, v. 8, n. 2. p. 91-98, 1997. 
VIEIRA, D.M. et al. Características microbiológicas de...

14. MACHADO, E.C.; SÁ, F. A qualidade dos sedimentos na área de influência das atividades do porto de Paranaguá, PR.: elementos traço e contaminantes orgânicos. Disponível em: http://www.abequa2005.geologia.ufrj.br/nukleo/pdfs/0308_eunice_machado.pdf. Consultado em: 15/03/2006.

15. MINISTÉRIO DA AGRICULTURA, DO ABSTECIMENTO E DA REFORMAAGRÁRIA. Métodos de análise microbiológica para alimentos. $1992-2^{\mathrm{a}}$ revisão.

16. VIEIRA, R.H. S. F. Microbiologia, higiene e qualidade do pescado. São Paulo: Livraria Varela. 2004.

17. TAOUKIS, P.S.; KOUTSOUMANIS, K.; NYCHAS, G.J.E. Use of time-temperature integrations end predictive modeling for shell life control of chilled fish under dynamic storage condition. Internacional Journal of Food Microbiology, n. 53, p. 21-31, 1999.

18. TRABULSI, I. R. Microbiologia. 2 ed. São Paulo: Atheneu, 1989. 386 p.

Recebido em 19/01/2005 Aceito em 24/05/2006 